\title{
RESEARCH
}

Open Access

\section{The efficacy of low dose short-term prednisone therapy for remission induction in newly diagnosed rheumatoid arthritis patients}

John M. Stacy ${ }^{1 \dagger}$, Jacob R. Greenmyer ${ }^{1 \dagger}$, James R. Beal ${ }^{2}$, Abe E. Sahmoun ${ }^{3}$ and Erdal Diri ${ }^{4^{*}}$ (D)

\begin{abstract}
Background: The ACR/EULAR recommendations endorse the use of glucocorticoids (GCs) for rheumatoid arthritis (RA) patients' flares and as a bridge to a DMARD. However, the recommendation of low dose short-term monotherapy with (GCs) remains open to the discretion of the clinician. The aim of this study was to assess whether a short-term use of low dose prednisone monotherapy was effective in inducing remission in newly diagnosed RA patients.

Methods: A retrospective analysis of patients newly diagnosed with RA at a Community Health Center in North Dakota was performed based on the ACR/EULAR RA classification criteria. Demographic and clinical data were abstracted from patients' medical charts. Patients treated with $(\leq 10 \mathrm{mg} /$ day) of prednisone up to 6 months were included. Response to prednisone was analyzed according to pre- and post-treatment DAS28-ESR score and EULAR response criteria.

Results: Data on 201 patients were analyzed. The mean prednisone dose was $8 \mathrm{mg} /$ day (range: 5-10; SD = 1.2) and the mean treatment duration was 42.2 days $(12-177 ; 16.9)$. Disease severity significantly improved from baseline to follow-up for: tender joint count ( $8.6 \pm 4.8$ vs. $1.5 \pm 3.3 ; P<0.001)$, swollen joint count $(6.2 \pm 5.0$ vs. $1.4 \pm 3.0 ; P<$ $0.001)$, and visual analog pain score ( $4.8 \pm 2.6$ vs. $2.1 \pm 2.5 ; P<0.001)$. DAS28-ESR disease severity significantly improved from baseline to follow-up: (5.1 \pm 1.2 vs. $2.7 \pm 1.3 ; P<0.001)$. Per EULAR response criteria, $69.7 \%$ of patients showed good response to treatment and $20.4 \%$ showed moderate response. $54.2 \%$ of patients reached remission.

Conclusion: Short-term use of low dose prednisone monotherapy induced disease remission and improved clinical severity of RA in the majority of newly diagnosed patients.
\end{abstract}

Keywords: Rheumatoid arthritis, Prednisone, Efficacy, Low dose, Short-term, Remission, Disease severity

\footnotetext{
* Correspondence: erdal.diri@trinityhealth.org

†John M. Stacy and Jacob R. Greenmyer contributed equally to the creation of this manuscript.

${ }^{4}$ Division of Rheumatology, Trinity Medical Group, Minot, ND, USA

Full list of author information is available at the end of the article
}

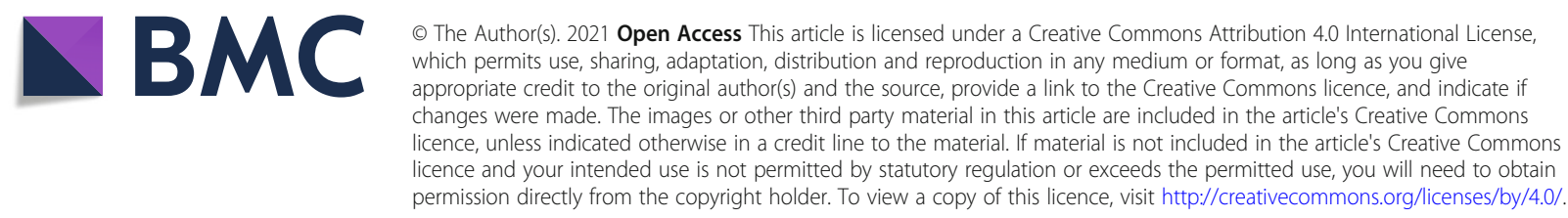




\section{Background}

Rheumatoid arthritis (RA) is a chronic, inflammatory synovial joint disorder characterized by symmetrical polyarticular arthritis [1]. The prevalence of RA has increased significantly, affecting 1.5 million adults in the U.S. [2].

RA is expensive not only for patients and payers through direct healthcare related costs, but also to society in the form of lost productivity secondary to the loss of functionality that comes with advanced disease [3, 4]. RA-associated morbidity is directly correlated with the amount of time patients spend in a state of severe disease activity [5]. Therefore, early intervention and optimal management is paramount to limiting long-term complications.

Glucocorticoids (GCs) were reported to be effective in treating RA as early as 1949 [6]. GCs have strong antiinflammatory properties that act quickly, and are therefore effective in inducing early remission in newly diagnosed RA patients while bridging to a synthetic disease-modifying anti-rheumatic drug (DMARD) and in fighting flares $[7,8]$.

The 2016 EULAR recommends that GCs be tapered as rapidly as clinically feasible, preferably within 3 months. However, they leave the dosing regimen and route of administration up to the decision of the individual rheumatologist [9]. Similarly, the 2015 ACR guidelines also acknowledge the efficacy of less than 3 months of low dose GC bridging therapy, but their dosing and administration recommendations are to some extent unclear [10].

Early RA has previously been defined as duration of symptoms for < 12 months [11]. For early RA, the international guidelines recommend the use of GCs without indicating the best starting dosage and duration of use of GCs [9-13]. Despite these shortcomings, GCs prescription rates remain high ranging from 30 to $74 \%$ [14-16]. The use of GCs as monotherapy has been overlooked in recent years and the risks of GC exposure vary widely based on patient characteristics [17].

The purpose of this study was to assess whether shortterm use of low dose prednisone monotherapy was effective in inducing remission in newly diagnosed RA patients.

\section{Methods}

\section{Study design}

A retrospective electronic medical records review was conducted of patients newly diagnosed with RA (ICD-9: 714) between January 1, 2005 and September 1, 2018 at a community medical center, North Dakota, USA. Diagnoses were made based on the ACR/EULAR 2010 RA classification criteria [18].

\section{Criteria of eligibility}

Inclusion criteria consisted of: newly diagnosed RA patients treated with $\leq 10 \mathrm{mg} /$ day of prednisone and had received a maximum of 6-month therapy. Patients were considered newly diagnosed if they had a duration of symptoms of less than 12 months. The international recommendations agree that a dose $<10 \mathrm{mg} /$ day GC is considered a low dose, and GC should be tapered in less than 3 months, or $7.5 \mathrm{mg} /$ day GC prescribed for up to 6 months [19]. Exclusion criteria were: 1) patients ever treated with a DMARD or started on a DMARD during the treatment period; 2) patients already actively on GCs upon entry into study; and 3) insufficient information in the electronic medical records to calculate disease severity.

The following variables were recorded for each patient: age, gender, race, prednisone dose, treatment duration, additional anti-inflammatory medications, rheumatoid factor status, rheumatoid factor titer, anti-cyclic citrullinated peptide antibody status, erythrocyte sedimentation rate, C-reactive protein, hemoglobin, platelets, tender joint count, swollen joint count, visual analogue scale, and DAS-28 ESR score. Response to prednisone treatment was calculated using the DAS-28 ESR score prior to initiating treatment and 6 weeks after initiation.

We computed: 1) the difference in DAS28-ESR score before and after prednisone treatment; 2) the disease activity severity score before and after treatment; and 3) the change via EULAR response criteria.

Disease activity severity DAS28-ESR was classified as: remission $(<2.6)$, low/minimal $(>2.6$ to $<3.2)$, moderate $(\geq 3.2$ to 5.1$)$, and high/severe $(>5.1)$. EULAR response criteria were used to compare improvement in DAS28-ESR scores with achieved disease severity upon follow up, taking into account both improvement in DAS28-ESR score over the study period as well as the absolute value of the DAS28-ESR score at the end of the study $[9,10,20]$.

\section{Statistical analysis}

SPSS 25.0 for Windows was used to analyze demographic and clinical characteristics of patients. Proportions and percentages were computed for each categorical variable. Paired t-tests were performed to determine which continuous variables were significantly different from one another. All $p$-values were two-sided, and $p$-value $<0.05$ was considered significant.

\section{Results}

Six hundred seventy-five patients were screened and 201 patients fulfilled the criteria (supplemental). The mean age (standard deviation) was $55.1 \pm 15.9$ years, $65.7 \%$ were female and $91.5 \%$ were white (Table 1 ). The mean 
Table 1 Characteristics of patients newly diagnosed with rheumatoid arthritis

\begin{tabular}{|c|c|}
\hline Number of patients & $N=201$ \\
\hline \multicolumn{2}{|l|}{ Age (years) } \\
\hline Mean \pm SD (Range) & $55.1 \pm 15.9(18-91)$ \\
\hline Gender, female n (\%) & $132(66)$ \\
\hline \multicolumn{2}{|c|}{ Time between symptom onset and diagnosis (days) } \\
\hline Mean \pm SD (Range) & $200.4 \pm 133.9(3-365)$ \\
\hline \multicolumn{2}{|c|}{ Treatment duration (days) } \\
\hline Mean \pm SD (Range) & $42.2 \pm 16.9(12-177)$ \\
\hline \multicolumn{2}{|l|}{ Race } \\
\hline White $n(\%)$ & $184(92)$ \\
\hline Other & $17(8)$ \\
\hline \multicolumn{2}{|c|}{ Prednisone dose (mg/day) } \\
\hline Mean \pm SD (Range) & $8.0 \pm 1.2(5-10)$ \\
\hline
\end{tabular}

$S D$ Standard Deviation

prednisone dose was $8.0 \pm 1.2 \mathrm{mg}$ and the mean treatment duration was $42.2 \pm 16.9$ days.

Clinical measures of disease severity significantly improved with reductions in tender joint count from baseline $8.6 \pm 4.8$ vs. $1.5 \pm 3.3$ at follow-up $(P<0.001)$, swollen joint count, $6.2 \pm 5.0$ vs. $1.4 \pm 3.0(P<0.001)$, and visual analog pain score, $4.8 \pm 2.6$ vs. $2.1 \pm 2.5(P<0.001)$ (Table 2$)$. Biomarkers of inflammation also showed significant improvement from baseline to follow-up with ESR decreasing from $33.7 \pm 22.6$ vs. $19.9 \pm 16.0(P<0.001)$ and a CRP from $2.5 \pm 3.2$ vs. $1.2 \pm 1.3(P<0.001)$ (Table 2$)$.

Overall, DAS28-ESR improved significantly from $5.1 \pm$ 1.2 baseline vs. $2.7 \pm 1.3$ at follow up $(P<0.001)$. DAS28ESR also significantly improved in both seropositive and seronegative patients from baseline to follow-up. In seropositive patients the mean DAS28-ESR changed from $5.2 \pm 1.1$ vs. $2.7 \pm 1.3(P<0.001)$ and in seronegative patients the mean DAS28-ESR changed from $4.9 \pm 1.2$ vs. $2.6 \pm 1.1(P<0.001)$ (Table 2).

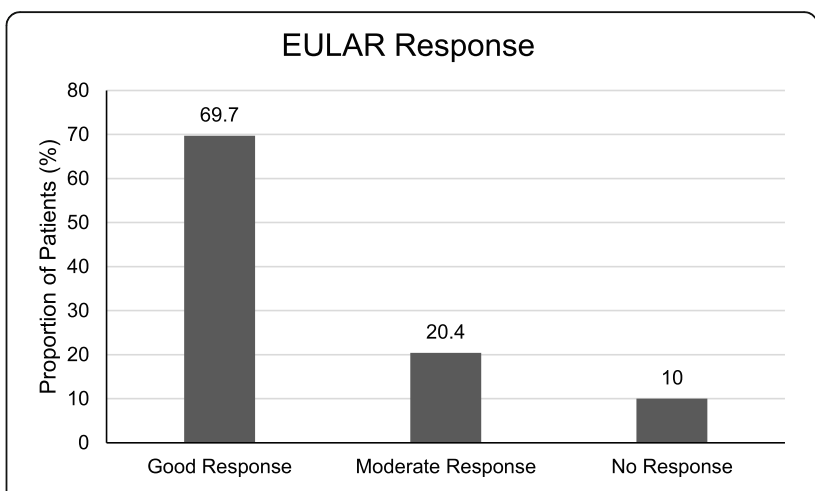

Fig. 1 Response rate based on EULAR criteria

Most patients showed marked improvement in disease severity at follow-up according to both DAS28-ESR severity classification and EULAR response criteria. According to the EULAR response criteria, the vast majority, $69.7 \%$ of the patients showed good response, with $20.4 \%$ showing moderate response and only $10 \%$ of the patients showing no response (Fig. 1). Prior to treatment, $95 \%$ of our patients exhibited either severe or moderate disease activity according to the DAS28-ESR classification (Fig. 2). Following treatment, $54.2 \%$ of patients had achieved remission, $16.9 \%$ exhibited low disease activity, with an additional $23.9 \%$ having moderate disease activity. Only 5\% displayed severe disease state (Fig. 3).

\section{Discussion}

This study found that low dose, short-term prednisone monotherapy significantly improved the disease severity indexes. Furthermore, the majority of patients achieved remission while only $5 \%$ still showed signs of severe disease. Early exposure to (GCs) in RA patients has been associated with improved outcomes and reduced need for biologicals [21-23].

Table 2 Response rate of disease activity measurements

\begin{tabular}{llll}
\hline & Baseline & Follow-up & $P$-value \\
\hline ESR, mean \pm SD mm/hr & $33.7 \pm 22.6$ & $19.9 \pm 16.0$ & $<0.001$ \\
CRP, mean \pm SD mg/L & $2.5 \pm 3.2$ & $1.2 \pm 1.3$ & $<0.001$ \\
Hemoglobin, mean \pm SD g/dL & $13.5 \pm 1.56$ & $13.9 \pm 1.42$ & $<0.001$ \\
Platelets, mean \pm SD 1000/mm ${ }^{3}$ & $163.1 \pm 174.4$ & $154.4 \pm 157.2$ & 0.02 \\
Tender joint count, mean \pm SD & $8.6 \pm 4.8$ & $1.5 \pm 3.3$ & $<0.001$ \\
Swollen Joint Count, mean \pm SD & $6.2 \pm 5.0$ & $1.4 \pm 3.0$ & $<0.001$ \\
Visual Analog Scale, mean \pm SD & $4.8 \pm 2.6$ & $2.1 \pm 2.5$ & $<0.001$ \\
DAS28-ESR, mean \pm SD & $5.1 \pm 1.2$ & $2.7 \pm 1.3$ & $<0.001$ \\
Seropositive, mean \pm SD $(n=134)$ & $5.2 \pm 1.1$ & $2.7 \pm 1.3$ & $<0.001$ \\
Seronegative, mean \pm SD $(n=67)$ & $4.9 \pm 1.2$ & $2.6 \pm 1.1$ & $<0.001$ \\
\hline
\end{tabular}

SD Standard deviation, ESR erythrocyte sedimentation rate, CRP C-reactive protein, DAS28 disease activity score at 28 joints 


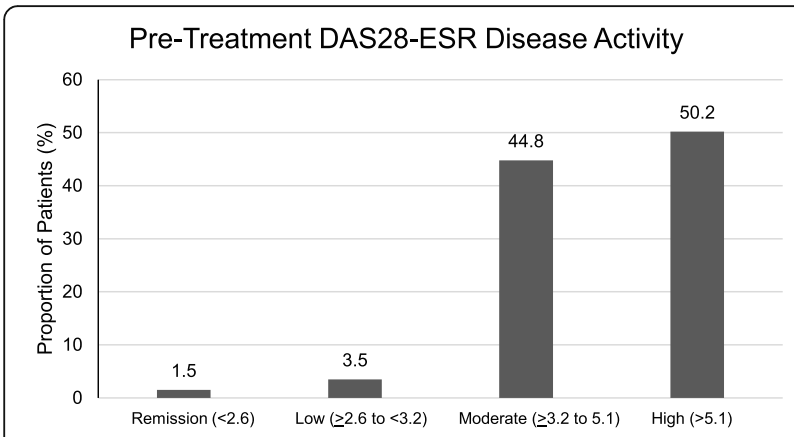

Fig. 2 DAS28-ESR severity prior to treatment

The BARFOT study found that $7.5 \mathrm{mg} / \mathrm{d}$ of prednisone resulted in $55.5 \%$ remission rate in newly diagnosed RA patients at 2 years [24]. A meta-analysis of 11 controlled trials also showed clinical improvement in disease after a month of treatment with low-dose GCs [8]. However, this analysis defined "low dose" as $<15 \mathrm{mg} /$ day, and included patients on bridging therapy as well as those on GC monotherapy.

The 2015 ACR guidelines recommend GC should be considered for short-term, defined as $<3$ months, in lowest possible dose in conjunction of a DMARD for early RA treatment (10). However. they did not defined the GC dose and left it to practitioner to decide. Therefore, particularly early RA patients are quite often overdosed with GC treatment with prednisone from 10 up to 60 mg daily that exposes RA patients to potentially multiple GC systemic toxicities. Our study suggests that low dose prednisone, $<10 \mathrm{mg}$ daily, is adequate for remission induction in a short period of time, in most of early RA patients. Furthermore, we have an experience that low dose prednisone is not only effective in remission induction, but also in even $5 \mathrm{mg}$ daily, can be as effective as a DMARD in maintenance of remission in a significant number of RA patients (data not shown).

While we did not document specific adverse events, several studies have assessed the safety profile related to low-dose prednisone [25-27]. A meta-analysis of six randomized trials (389 patients, average dose of prednisone

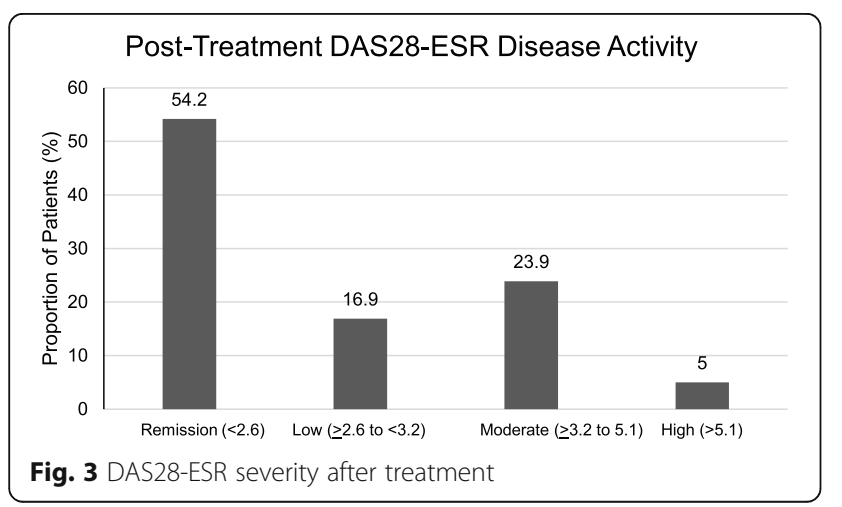

equivalent: $5-10 \mathrm{mg} /$ day for at least 2 years) revealed a good efficacy to toxicity ratio with a number needed to harm/number needed to treat of 0.25 [28]. The ESPOIR study found that low-dose $(<5 \mathrm{mg} / \mathrm{d})$ prednisone therapy for 6 months was not associated with significant side effects [29]. The GLORIA trial is currently underway to evaluate the safety and effectiveness of low dose GC therapy ( $5 \mathrm{mg} /$ day prednisone for 2 years) versus placebo in 800 elderly patients with RA and might soon provide valuable new evidence [30]. Waljee et al. [31] found that even short-term GC exposure was associated with venous thromboembolism, fractures and sepsis. In the Rabbit registry [32], the overall risk of death was increased in a manner independent of the activity of the disease for daily doses of GC greater than $5 \mathrm{mg} / \mathrm{d}$ (an increase of $40 \%$ in the risk for doses comprised between 5 and $10 \mathrm{mg} /$ day). Glucocorticoid use in RA is associated with a dosedependent increase in mortality rates, with a daily threshold dose of $8 \mathrm{mg}$, at which the number of deaths increased in a dose-dependent manner [33, 34]. Standardized guidelines on RA evaluation of adverse events are lacking.

We acknowledge some limitations inherent to this study. First, these data are retrospectively obtained from electronic medical records of RA patients that carries potential multiple variables effecting results. Second, vast majority of analyzed patients are white not reflecting racial differences. Third, missing data related exclusion of patients may cause selection bias. Nonetheless, we believe the strength of our study is including quite homogeneous data, obtained from a single practice, that minimizes most of above concerns.

\section{Conclusions}

Our study showed that low dose and short-term GC monotherapy to be efficacious in inducing remission in newly diagnosed RA patients. These findings may assist clinicians in selecting the appropriate prednisone dosage and duration of use, as a first line monotherapy, for newly diagnosed RA patients. The side effects of GCs are clearly dose- dependent but are also affected by patient's risk factors, which should be considered when GCs are prescribed. More research needs to be done to perform side effects of induction with low dose GC monotherapy vs. alternative therapies and the long term consequences of both therapies for matched treatment groups.

\section{Supplementary Information}

The online version contains supplementary material available at https://doi. org/10.1186/s42358-021-00205-4.

Additional file 1: Supplemental 1. Electronic medical record search

results and case inclusion.

Acknowledgements

Not applicable. 


\section{Authors' contributions}

ED conceived the hypothesis, provided clinical guidance, and interpretation of the findings, JG and JS performed data collection and drafted the manuscript. JB participated in study design, conducted data analysis, and edited the final manuscript. AS participated in the study design, updated the literature review, and edited the final manuscript. The authors read and approved the final manuscript.

\section{Funding}

None.

\section{Availability of data and materials}

The outputs are available from the authors upon request.

\section{Declarations}

\section{Ethics approval and consent to participate}

The study was approved by the Institutional Review Boards of community medical center and the University of North Dakota.

\section{Consent for publication}

Not applicable.

\section{Competing interests}

All authors have no competing interests.

\section{Author details}

'University of North Dakota School of Medicine and Health Sciences, Grand Forks, ND, USA. ${ }^{2}$ Department of Family and Community Medicine, University of North Dakota School of Medicine and Health Sciences, Grand Forks, ND, USA. ${ }^{3}$ Department of Internal Medicine, University of North Dakota School of Medicine and Health Sciences, Forks, ND, USA. ${ }^{4}$ Division of Rheumatology, Trinity Medical Group, Minot, ND, USA.

Received: 4 December 2020 Accepted: 1 July 2021

\section{Published online: 09 August 2021}

\section{References}

1. Aletaha D, Smolen JS. Diagnosis and Management of Rheumatoid Arthritis: a review. JAMA. 2018;320(13):1360-72. https://doi.org/10.1001/jama.2018.13103.

2. Kawatkar AA, Gabriel SE, Jacobsen SJ. Secular trends in the incidence and prevalence of rheumatoid arthritis within members of an integrated health care delivery system. Rheumatol Int. 2019;39(3):541-9. https://doi.org/10.1 007/s00296-018-04235-y.

3. Kobelt G, Woronoff AS, Richard B, Peeters P, Sany J. Disease status, costs and quality of life of patients with rheumatoid arthritis in France: the ECOPR study. Joint Bone Spine. 2008;75(4):408-15. https://doi.org/10.1016/j. jbspin.2007.07.015.

4. Van den Hoek J, Boshuizen HC, Roorda LD, Tijhuis GJ, Nurmohamed MT, van den Bos GA, et al. Mortality in patients with rheumatoid arthritis: a 15year prospective cohort study. Rheumatol Int. 2017;37(4):487-93. https://doi. org/10.1007/s00296-016-3638-5.

5. Listing J, Kekow J, Manger B, Burmester GR, Pattloch D, Zink A, et al. Mortality in rheumatoid arthritis: the impact of disease activity, treatment with glucocorticoids, TNFa inhibitors and rituximab. Ann Rheum Dis. 2015; 74(2):415-21. https://doi.org/10.1136/annrheumdis-2013-204021.

6. Hench PS, Kendall EC, Slocumb CH, Polley HF. The effect of a hormone of the adrenal cortex (17-hydroxy-11-dehydrocorticosterone: compound E) and of pituitary adrenocortical hormone in arthritis: preliminary report. Ann Rheum Dis. 1949;8(2):97-104. https://doi.org/10.1136/ard.8.2.97.

7. Palmowski Y, Buttgereit T, Dejaco C, Bijlsma JW, Matteson EL, Voshaar M, et al. "Official View" on glucocorticoids in rheumatoid arthritis: a systematic review of international guidelines and consensus statements. Arthritis Care Res. 2017;69:1134-41.

8. Gøtzsche PC, Johansen HK. Short-term low-dose corticosteroids vs placebo and nonsteroidal anti-inflammatory drugs in rheumatoid arthritis. Cochrane Database Syst Rev. 2005(1):CD000189.

9. Smolen JS, Landewé R, Bijlsma J, Burmester G, Chatzidionysiou K, Dougados $M$, et al. EULAR recommendations for the management of rheumatoid arthritis with synthetic and biological disease-modifying anti-rheumatic drugs: 2016 update. Ann Rheum Dis. 2017;76(6):960-77. https://doi.org/ 0.1136/annrheumdis-2016-210715.

10. Singh JA, Saag KG, Bridges SL Jr, Akl EA, Bannuru RR, Sullivan MC, et al. American College of Rheumatology guideline for the treatment of rheumatoid arthritis. Arthritis Rheum. 2016;68:1-26.

11. Heidari B. Rheumatoid arthritis: early diagnosis and treatment Outcoms. Caspian J Intern Med. 2011;2(1):161-70.

12. GUIPCAR Group. Update of the clinical practice guideline for the management of rheumatoid arthritis in Spain. 2011.

13. Lau CS, Chia F, Harrison A, Hsieh TY, Jain R, Jung SM, et al. APLAR rheumatoid arthritis treatment recommendations. Int J Rheum Dis. 2015; 18(7):685-713. https://doi.org/10.1111/1756-185X.12754.

14. Black RJ, Joseph RM, Brown B, Movahedi M, Lunt M, Dixon WG. Half of UK patients with rheumatoid arthritis are prescribed oral glucocorticoid therapy in primary care: a retrospective drug utilization study. Arthritis Res Ther. 2015;17(1):375. https://doi.org/10.1186/s13075-015-0895-8.

15. Yamanaka H, Askling J, Berglind N, Franzen S, Frisell T, Garwood C, et al. Infection rates in patients from five rheumatoid arthritis (RA) registries: contextualizing an RA clinical trial programme. RMD Open. 2017;3(2): e000498. https://doi.org/10.1136/rmdopen-2017-000498.

16. Caplan L, Wolfe F, Russell AS, Michaud K. Corticosteroid use in rheumatoid arthritis: prevalence, predictors, correlates, and outcomes. J Rheumatol. 2007;34(4):696-705.

17. Strehl C, Bijlsma JW, de Wit M, Boers M, Caeyers N, Cutolo M, et al. Defining conditions where long-term glucocorticoid treatment has an acceptably low level of harm to facilitate implementation of existing recommendations: view points from an EULAR task force. Ann Rheum Dis. 2016;75(6):952-7. https://doi.org/10.1136/annrheumdis-2015-208916.

18. Kay J, Upchurch KS. ACR/EULAR 2010 rheumatoid arthritis classification criteria. Rheumatology. 2012;51(suppl. 6):vi5-9.

19. Gaujoux-Viala C, Gossec L. When and for how long should glucocorticoids be used in rheumatoid arthritis? International guidelines and recommendations. Ann N Y Acad Sci. 2014;1318(1):32-40. https://doi.org/10.1111/nyas.12452.

20. Fransen J, Van Riel PL. The disease activity score and the EULAR response criteria. Clin Exp Rheumatol. 2005;23:S93.

21. Safy M, Jacobs JWG, liff ND, Bijlsma JWJ, van Laar JM, de Hair MJH, et al. Long-term outcome is better when a methotrexate-based treatment strategy is combined with $10 \mathrm{mg}$ prednisone daily: follow-up after the second Computer-Assisted Management in Early Rheumatoid Arthritis trial. Ann Rheum Dis. 2017:76:1432-5.

22. Jacobs JW, Van Everdingen AA, Verstappen SM, Bijlsma JW. Follow up radiographic data on patients with rheumatoid arthritis who participated in a two-year trial of prednisone therapy or placebo. Arthritis Rheum. 2006; 54(5):1422-8. https://doi.org/10.1002/art.21809.

23. Van Tuyl LH, Boers M, Lems WF, Landewé RB, Han H, Van der Linden S, et al. Survival, comorbidities and joint damage 11 years after the COBRA combination therapy trial in early rheumatoid arthritis. Ann Rheum Dis. 2010;69(5):807-12. https://doi.org/10.1136/ard.2009.108027.

24. Galicia-Hernandez G, Parra-Salcedo F, Ugarte-Martinez P, Contreras-Yanez I, Ponce-de-Leon A, Pascual-Ramos V. Sustained moderate-to-high disease activity and higher Charlson score are predictors of incidental serious infection events in RA patients treated with conventional disease-modifying anti-rheumatic drugs: a cohort study in the treat-to-target era. Clin Exp Rheumatol 2016;34:261-69.

25. Svensson B, Boonen A, Albertsson K, Van Der Heijde D, Keller C, Hafstrom I. Low-dose prednisolone in addition to the initial disease-modifying antirheumatic drug in patients with early active rheumatoid arthritis reduces joint destruction and increases the remission rate: a two-year randomized trial. Arthritis Rheum. 2005;52(11):3360-70. https://doi.org/10.1002/art.21298.

26. Van der Goes MC, Jacobs JW, Boers M, Andrews T, Blom-Bakkers MA, Buttgereit $F$, et al. Monitoring adverse events of low-dose glucocorticoid therapy: EULAR recommendations for clinical trials and daily practice. Ann Rheum Dis. 2010;69(11):1913-9. https://doi.org/10.1136/ard.2009.124958.

27. Da Silva JA, Jacobs JW, Bijlsma JW. Revisiting the toxicity of low-dose glucocorticoids: risks and fears. Ann N Y Acad Sci. 2006;1069(1):275-88. https://doi.org/10.1196/annals.1351.026.

28. Montecucco C, Todoerti M, Sakellariou G, Scirè CA, Caporali R. Lowdose oral prednisone improves clinical and ultrasonographic remission rates in early rheumatoid arthritis: results of a 12-month open-label randomized study. Arthritis Res Ther. 2012;14(3):R112. https://doi.org/1 $0.1186 / a r 3838$. 
29. Roubille C, Rincheval N, Dougados M, Flipo RM, Daures JP, Combe B. Sevenyear tolerability profile of glucocorticoids use in early rheumatoid arthritis: data from the ESPOIR cohort. Ann Rheum Dis. 2017;76(11):1797-802. https:// doi.org/10.1136/annrheumdis-2016-210135.

30. Ravindran V, Rachapalli S, Choy EH. Safety of medium- to long-term glucocorticoid therapy in rheumatoid arthritis: a meta-analysis. Rheumatology. 2009;48(7):807-11. https:/doi.org/10.1093/rheumatology/kep096.

31. Hartman L, Rasch LA, Klausch T, Bijlsma HW, Christensen R, Smulders YM, et al. Harm, benefit and costs associated with low-dose glucocorticoids added to the treatment strategies for rheumatoid arthritis in elderly patients (GLORIA trial): study protocol for a randomized controlled trial. Trials. 2018; 19(1):67. https://doi.org/10.1186/s13063-017-2396-3.

32. Waljee AK, Rogers MAM, Lin P, Singal AG, Stein JD, Marks RM, et al. Shortterm use of oral corticosteroids and related harms among adults in the United States: population based cohort study. BMJ. 2017:357:j1415.

33. Listing J, Kekow J, Manger B, Burmester GR, Pattloch D, Zink A, et al. Mortality in rheumatoid arthritis: the impact of disease activity, treatment with glucocorticoids, TNFa inhibitors and rituximab. Ann Rheum Dis. 2015; 74(2):415-21. https://doi.org/10.1136/annrheumdis-2013-204021.

34. del Rincón I, Battafarano DF, Restrepo JF, Erikson JM, Escalante A. Glucocorticoid dose thresholds associated with all-cause and cardiovascular mortality in rheumatoid arthritis. Arthritis Rheum. 2014;66(2):264-72. https:// doi.org/10.1002/art.38210.

\section{Publisher's Note}

Springer Nature remains neutral with regard to jurisdictional claims in published maps and institutional affiliations.

Ready to submit your research? Choose BMC and benefit from:

- fast, convenient online submission

- thorough peer review by experienced researchers in your field

- rapid publication on acceptance

- support for research data, including large and complex data types

- gold Open Access which fosters wider collaboration and increased citations

- maximum visibility for your research: over $100 \mathrm{M}$ website views per year

At $\mathrm{BMC}$, research is always in progress.

Learn more biomedcentral.com/submissions 